\title{
Depressive symptoms are common among rural Malawian adolescents
}

\section{Teivaanmaki, T.}

2018-07

Teivaanmaki , T , Cheung , Y B , Maleta , K , Gandhi , M \& Ashorn , P 2018 , ' Depressive symptoms are common among rural Malawian adolescents ' , Child: Care, Health and Development , vol. 44 , no. 4 , pp. 531-538 . https://doi.org/10.1111/cch.12567

http://hdl.handle.net/10138/303852

https://doi.org/10.1111/cch.12567

unspecified

publishedVersion

Downloaded from Helda, University of Helsinki institutional repository.

This is an electronic reprint of the original article.

This reprint may differ from the original in pagination and typographic detail.

Please cite the original version. 


\title{
Depressive symptoms are common among rural Malawian adolescents
}

\author{
T. Teivaanmäki'1,2 D | Y. B. Cheung ${ }^{3}$ | K. Maleta ${ }^{4}$ | M. Gandhi ${ }^{1,3,5}$ | P. Ashorn ${ }^{6}$
}

${ }^{1}$ Center for Child Health Research, University of Tampere, Faculty of Medicine and Life,

Tampere, Finland

${ }^{2}$ Department of Paediatrics, Helsinki University Hospital, Helsinki, Finland

${ }^{3}$ Centre for Quantitative Medicine, DukeNational University of Singapore Medical School, Singapore, Singapore

${ }^{4}$ School Of Public Health and Family Medicine, College Of Medicine, University of Malawi, Blantyre, Malawi

${ }^{5} \mathrm{Head}$ of Biostatisctics, Singapore Clinical Research Institute, Singapore, Singapore

${ }^{6}$ Center for Child Health Research, University of Tampere, Faculty of Medicine and Life Sciences and Tampere University Hospital, Department of Paediatrics, Tampere, Finland

Correspondence

Tiina Teivaanmäki, Pediatrician, MD, Center for Child Health Research, University of Tampere, Faculty of Medicine and Life, Arvobuilding, FIN-33014 Tampere, Finland.

Email: tiina.teivaanmaki@gmail.com

Funding information

Suomen Akatemia, Grant/Award Number: 252075; Academy of Finland, Grant/Award Number: 252075

\begin{abstract}
Background: Depressive conditions cause about 25 million disability adjusted life years in low-income countries annually. The incidence of depression rises after puberty, and the young age distribution in these countries may cause a high burden of adolescent depression. We aimed to assess the prevalence of reported depressive symptoms among rural adolescents in Malawi. Additionally, we assessed the association between birth weight, childhood growth, gender, and pubertal maturity and depressive symptoms.
\end{abstract}

Methods: We followed 767 children from the foetal period until 15-years-of-age. We used the Short Mood and Feelings Questionnaire (SMFQ) to examine reported depressive symptoms at 15 years. The questionnaire was translated to local language and then back-translated until inaccuracies were not detected. Anthropometry was conducted at 1, 24, 120, and 180 months of age. We performed regression models with imputed data to assess associations between the independent variables and depressive symptoms. As a sensitivity analysis, we ran the same regression models with participants with no missing data.

Results: A total of 523 participants were seen at 15 years. The mean SMFQ score was 15 with $90 \%$ (95\% $\mathrm{Cl} 87-92 \%$ ) of the participants scoring $\geq 11$ points, the traditional cutoff for screening for depression. Birth weight, growth, gender, and pubertal maturity were not associated with the SMFQ score in the primary imputed analyses. In the sensitivity analysis, birth weight was associated with the SMFQ score in all models.

Conclusions: The prevalence of reported depressive symptoms was high among the studied population. It is uncertain how well the traditional cut-off of 11 points identifies children with clinically significant depressive symptoms in our sample. Our data do not support a hypothesis of an association between growth, gender, or pubertal maturity and depressive symptoms. Nevertheless, our results highlight the importance of the awareness of mental health problems in low-income countries.

\section{KEYWORDS}

adolescent, depression, growth, stunting

\section{1 | INTRODUCTION}

It is estimated that depression caused over 26.5 million disability adjusted life years in low- or middle-income settings in 2004. (World
Health Organization; WHO, 2008). Estimates of the prevalence of adolescent depression vary. In sub-Saharan Africa, approximately $14 \%$ of children suffer from psychological disorders (Cortina, Sodha, Fazel, \& Ramchandani, 2012; Patel, Flisher, Hetrick, \& McGorry, 2007). 
The incidence of depression rises after puberty, and the young age distribution in low-income countries results in a high burden of adolescent depression. However, child and adolescent mental health services are rarely available (Angold, Costello, \& Worthman, 1998; Patel et al., 2007).

The aetiology of adolescent depression is multifactorial. It has been mostly studied in developed countries. In addition to a genetic tendency for the disease, social disadvantage, parental mental disorders, female gender, and experiences of violence are related to depression (Patel et al., 2007). Low birth weight, growth failure, and malnutrition early in life may also contribute to later depressive symptoms, but the significance of childhood growth is unknown (de Mola et al., 2015; Galler et al., 2010; Walker, Chang, Powell, Simonoff, \& Grantham-McGregor, 2007). Since brain development continues throughout childhood, malnutrition may lead to neurodevelopmental disorders into adolescence (Teivaanmaki, Cheung, Kortekangas, Maleta, \& Ashorn, 2015; Thompson, 2001). The timing of puberty is influenced by possible growth failure and catch-up growth (Angold et al., 1998; Proos, 2012), and the stage of pubertal maturity is therefore important when evaluating the association between growth and depression. To our knowledge, this information has not been collected before.

The primary objective of this study was to describe the prevalence of reported depressive symptoms at 15 years of age in a rural Malawian cohort. The secondary objective was to assess the associations between birth weight, growth, gender, and pubertal maturation and depressive symptoms in adolescence, particularly in the sub-Saharan adolescent population.

\section{I PARTICIPANTS AND METHODS}

\section{1 | Study design}

This prospective cohort study was conducted in Lungwena, Mangochi District, Southern Malawi. Covering approximately $100 \mathrm{~km}^{2}$, the study area included 26 villages and 23,000 inhabitants, who were mostly Muslims of the Yao tribe. The literacy rate was low, and the main income sources were farming and fishing.

The study cohort was enrolled between June 1995 and August 1996. It comprised 795 mothers who attended the antenatal clinic at Lungwena Health Centre (Maleta, Virtanen, Espo, Kulmala, \& Ashorn, 2003). These pregnant women carried 813 foetuses, and the number of children born live was 767 (Figure 1). There were 759 children alive after the first day of life. These cohort members were followed up until 15 years of age. Anthropometry was conducted at birth and at $1,24,120$, and 180 months (15 years), and depressive symptoms and pubertal maturity were examined at 15 years of age. We then examined the magnitude of depressive symptoms and assessed the association between the change in length-for-age/height-for-age z-scores (LAZ/HAZ) at the aforementioned age intervals, birth weight, gender, and pubertal maturation and depressive symptoms.

Ethical approval for the Lungwena Child Survival Study was obtained from the National Health Science Research Committee in Malawi (HSRC 93/94) and the College of Medicine Research and

\section{Key messages:}

- Reported depressive symptoms are common among rural Malawian adolescents.

- Birth weight may affect later mental health.

- Height gain in childhood, gender, and pubertal maturity at the time of the assessment did not predict depressive symptoms at 15 years of age.

- Awareness of depressive symptoms and the allocation of resources to mental health problems in low-income countries should be increased.

Ethics Committee (P04.05.314). Informed consent was obtained from each guardian at the beginning of the study and again from each guardian and adolescent before the visit at 15 years.

\section{2 | Data collection}

We used the Short Mood and Feelings Questionnaire (SMFQ) to assess the adolescents' reported depressive symptoms at 15 years of age. A public health scientist translated the questionnaire from English to the Yao language, and a psychologist back-translated it to English. The translation was then revised until inaccuracies were not detected. The SMFQ provides a reliable measure of depressive symptoms in children of a variety of ages (Angold et al., 1995; Turner, Joinson, Peters, Wiles, \& Lewis, 2014). It contains 13 questions with three response options, true ( 2 points), sometimes true ( 1 point), and not true ( 0 points). The range is $0-26$ points, and a score $\geq 11$ is suggested to refer to significant depressive symptoms. The SMFQ includes individual items such as "I felt miserable or unhappy" or "I didn't enjoy anything at all." With the generally used 11-point cut-off, the specificity of the questionnaire is $83 \%$ for identifying those who meet the ICD - 10 criteria for depression, and the sensitivity is 71\% (Turner et al., 2014). One third of the participants were considered to have fluent literacy skills (as evaluated via a reading test) and self-administered the questionnaires. The rest were interviewed. The pubertal stage of the participants was assessed by trained research assistants at 15 years of age with the Tanner classification (Tanner, 1962). It includes five stages (I-V) for pubic hair development for both sexes and genitalia development for boys and breast development for girls. Cognitive capacity, which was added in one of the models as a potential intermediate variable was examined with Raven's Coloured Matrices (Raven, Raven, \& Court, 1998; Teivaanmäki et al., 2017).

Using regression analysis, we studied the association of birth weight and height gain between 1 and 24 months, 24 and 120 months, and 120 and 180 months (15 years) and depressive symptoms at 15 years. The first weight measurement, taken during the first 7 days of life, was used as a proxy for birth weight. It reflects foetal growth and possible adverse exposures during pregnancy. The three age intervals represent growth until the first 1,000 days of life, the latent growth period, and prepubertal and pubertal growth. Procedures for anthropometric measurements have been described previously (e.g., 


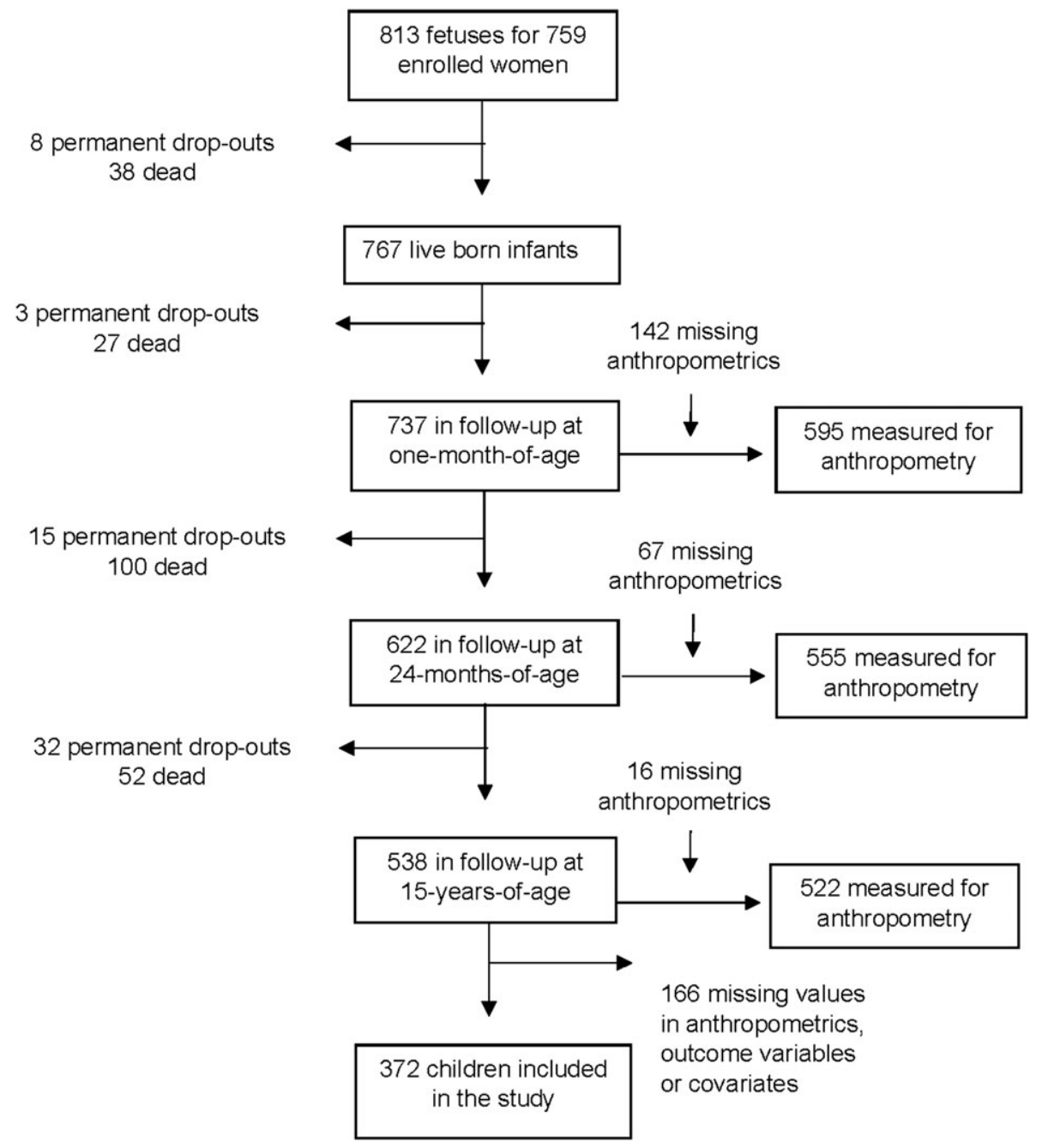

FIGURE 1 The flow of study participants

Maleta et al., 2003). Briefly, the data collectors measured the participants' weight during the first 7 days and length at 1 month at their homes. Length was measured with locally constructed length boards. The measurements at 24 months were taken with a self-made height board at the participants' homes, and the measurements at 120 and 180 months were taken with a stadiometer (Harpenden, Holtain Limited, UK) at the study clinic. The study team calibrated the equipment weekly, and the data collectors were trained and retrained by the investigators at intervals of 1-36 months.

To derive length-for-age/height-for-age $z$-scores (LAZ/HAZ), we used the WHO Multicentre Growth Reference Study (WHO Multicentre Growth Reference Study Group, 2006) for children at one and 24 months of age and the WHO Reference 2007 (De Onis et al., 2007) at 120 and 180 months. Reference values for supine length were used for the measurements at 1 month and standing height for $\geq 24$ months. We used two closely aligned WHO references to cover the whole range of growth in the cohort. We generated the $z$ scores for anthropometric measurements using a Stata macro (Vidmar, Cole, \& Pan, 2013).

We added potential confounders and mediators to the regression models. The wealth index was assessed during pregnancy by interviewing the mothers. It summarizes the household ownership of radios, bicycles/tricycles, mattresses, and livestock ownership of land per person and the number of family supporters. It was derived from factor analysis and categorized into three levels: poor (below the 40th percentile), middle (40th to 80th percentiles), and rich (top 20th percentile). The gestational duration was estimated with a national chart for fundal height during the antenatal visits. Information about the timing of menstrual periods was not reliable, and ultrasound was not available (Kulmala et al., 2000).

\section{3 | Statistical analyses}

In the primary regression analysis, we used multiple imputation to impute missing data. All missing data in the independent and dependent variables and potential confounders were imputed for the 523 participants who attended the examination at 15 years. Multiple imputation by chained regression was used to allow for missing values in more than one variable (White, Royston, \& Wood, 2011). We used 50 sets of imputation (White et al., 2011), and the 50 sets of data were pooled using Rubin's rule (Rubin, 1987).

We assessed the associations between birth weight; linear growth from birth to 24 months, 24-120 months, and 120-180 months (15 years); and depressive symptoms at 15 years using three 
regression models. Model 1 simultaneously included birth weight (grams), HAZ at 1 month (HAZ_1), 24 months (HAZ_24), 120 months (HAZ_120), and 15 years (HAZ_180) as exposure variables without any confounder adjustments. Model 2 was adjusted for gender, gestational duration (weeks), father's occupation, father's literacy, mother's literacy, and the wealth index (Filmer \& Pritchett, 2001). Model 3 was further adjusted for the Raven's Coloured Matrices score at 15 years (Raven et al., 1998; Teivaanmäki et al., 2017) and pubertal stage. This model aimed to assess the potential role of cognitive function and pubertal maturity as intermediate variables through which HAZ might affect depression.

As a sensitivity analysis, we performed the same regression models with all the cohort members who had no missing values in any of the variables, without using multiple imputations. We performed all analyses using Stata 12.1 (Stata Corporation, College Station, TX, USA).

\section{3 | RESULTS}

Of the 767 infants, 759 survived the first day of life and were included in the cohort. After the first day, 171 (23\%) died and 50 (7\%) permanently dropped out prior to the follow-up at 15 years. After the deaths and dropouts, there were 538 participants in the 15-year assessments, of whom 523 had data in one or more of the outcome variables and were included in the imputed analyses. Out of 523 participants, 287 had missing values in one or more of the exposure or outcome variables. Thus, 236 participants with no missing values were included in the sensitivity analysis (Figure 1).

Among the 523 participants, the mean (SD) duration of pregnancy was 39.1 weeks (3.3), and the newborn weight was 3,110 g (519). Some $20 \%$ were born preterm (<37 completed gestation weeks), and
9\% presented with low newborn weight $(<2,500 \mathrm{~g})$. The sociodemographic baseline characteristics were substantially similar for the participants and those excluded because of death, loss to follow-up, or missing data (Table 1).

The majority of the SMFQ assessments (77\%) were interviewer administered. Among the 523 participants who were measured for anthropometrics at 15 years of age, the mean (SD) of HAZ at 1, 24, 120 and 180 months was -1.7 (1.2), -2.9 (1.2), -1.7 (0.8), and -1.7 (1.0), respectively. Mean (SD, range) SMFQ score was 15.0 (4.2, 0-26) points: $14.9(4.0,0-26)$ for male and $15.0(4.4,0-26)$ for female $(p=.72$; Table 2$)$. Of all participants $(N=458), 90 \%(95 \% \mathrm{Cl}$ $87-92 \%)$ scored $\geq 11$ points. Corresponding figures for males and females separately were $92 \%(95 \% \mathrm{Cl} 88-95 \% ; n=231)$ and $88 \%(95 \% \mathrm{Cl} 83-91 \% ; n=227)$, respectively $(p=.07$; Table 2$)$. The distribution of SMQF scores by gender is shown in Figure 2. Over $12 \%(95 \% \mathrm{Cl} 9-15 \% ; n=62)$ of the participants scored $\geq 20$ points (Figure 3). The proportions of participants classified as screen positive according to different cut-off values are presented in Figure 3.

In the regression analyses with the imputed data, when birth weight and HAZ at 1, 24, 120 months, and 15 years were simultaneously included in the analysis (Model 1), birth weight (gram) was not statistically significantly associated with SMFQ score (coefficient $=-0.87, p=.133$; Table 3 ). Height gains between different time periods were not statistically significantly associated with SMFQ score. The coefficients were $0.11(p=.643)$ at 1 month, -0.12 $(p=.536)$ at 24 months, $-0.03(p=.932)$ at 120 months, and 0.15 $(p=.559)$ at 15 years (Table 3 ). Similar results were found in Model 2, adjusted for the potential confounders, and in Model 3, further adjusted for Raven's Coloured Matrices and pubertal maturity (Table 3). Neither pubertal maturity nor sex were statistically significantly associated with depressive symptoms (Table 3 ).

TABLE 1 Participant characteristics

\begin{tabular}{|c|c|c|c|}
\hline Variables & Included $(n=523)$ & Excluded $^{\mathrm{a}}(n=235)$ & $p$ value \\
\hline Gender, male \% (n) & 49 (259) & $55(130)$ & .133 \\
\hline Mean birth weight, ${ }^{\mathrm{b}} \mathrm{g}(S D)$ & $3,110(519)$ & $2,990(485)$ & .015 \\
\hline Low birth weight, & $9(30)$ & $12(18)$ & .222 \\
\hline Mean gestational age, weeks (SD) & $39.1(3.3)$ & $39.1(3.2)$ & .971 \\
\hline Preterm births (<37 gestational weeks), \% (n) & $20(103)$ & $19(42)$ & .678 \\
\hline \multicolumn{4}{|l|}{ Wealth index, \% (n) } \\
\hline Poor & $38(194)$ & $44(97)$ & \multirow{3}{*}{.351} \\
\hline Middle & $39(201)$ & $37(82)$ & \\
\hline Rich & $23(116)$ & $20(44)$ & \\
\hline \multicolumn{4}{|l|}{ Father's occupation, \% (n) } \\
\hline Fisherman & $40(208)$ & $35(78)$ & \multirow{4}{*}{.420} \\
\hline Other & $22(112)$ & $26(59)$ & \\
\hline Trader & $19(99)$ & $19(42)$ & \\
\hline Farmer & $19(97)$ & $20(45)$ & \\
\hline Father's literacy, Literate, \% (n) & $42(218)$ & $44(99)$ & .623 \\
\hline Mother's literacy, Literate, \% (n) & $14(70)$ & $15(33)$ & .674 \\
\hline
\end{tabular}

${ }^{a}$ Excluded because of death, loss to follow-up, or missing values. The final numbers of participants in the comparison vary between 496 and 759 .

${ }^{b}$ Measured at $\leq 7$ days of age.

${ }^{\mathrm{c}}$ Low birth weight $<2,500 \mathrm{~g}$. 
TABLE 2 Summary of the SMFQ results at 15 years

\begin{tabular}{|lllll|} 
& $\begin{array}{l}\text { All } \\
(\mathrm{N}=509)\end{array}$ & $\begin{array}{l}\text { Male } \\
(\boldsymbol{n}=250)\end{array}$ & $\begin{array}{l}\text { Female } \\
(\boldsymbol{n}=259)\end{array}$ & $\begin{array}{l}\boldsymbol{p} \\
\text { value }\end{array}$ \\
\hline Mean (SD) & $15.0(4.2)$ & $14.9(4.0)$ & $15.0(4.4)$ & $.72^{*}$ \\
\hline $\begin{array}{c}\mathrm{N}(\%) \text { with SMFQ } \\
\text { score } \geq 11\end{array}$ & $458(90 \%)$ & $231(92 \%)$ & $227(88 \%)$ & $.07^{* *}$ \\
\hline
\end{tabular}

Note. SMFQ = Short Mood and Feelings Questionnaire.

${ }^{*}$ The comparison between male and female was done with $t$ test.

${ }^{* *}$ The comparison between male and female was done with chi-square test.

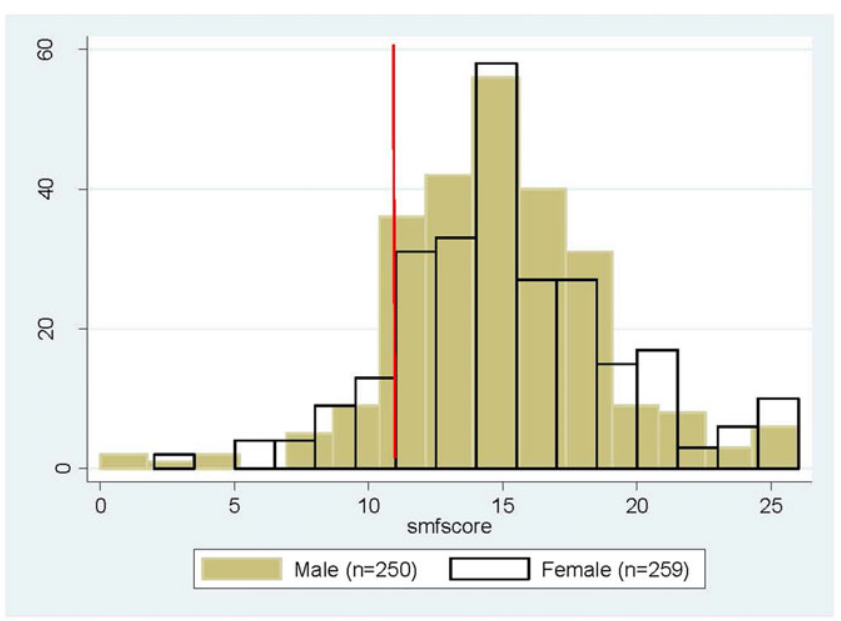

FIGURE 2 Short Mood and Feelings Questionnaire score for those boys and girls who were examined at 15 years. The red line is the traditional cut-off (11 points) for clinically significant depressive symptoms [Colour figure can be viewed at wileyonlinelibrary.com]

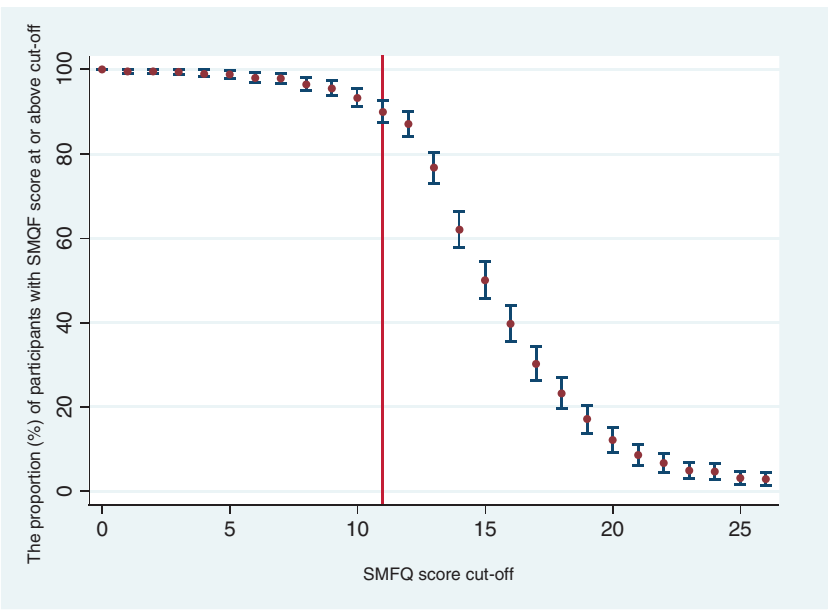

FIGURE 3 Proportion of participants categorized as having a positive screening test result by Short Mood and Feelings Questionnaire (SMQF) score cut-offs. The error bars indicate 95\% confidence intervals for the proportion [Colour figure can be viewed at wileyonlinelibrary.com]

In the sensitivity analyses with the completely observed data ( $n=236$ ), birth weight (grams) was statistically significantly associated with SMFQ score in Model 1 (coefficient $=-1.58, p=.014$ ), Model 2 (coefficient $=-1.45, p=.034$ ), and Model 3 (coefficient $=-1.38$, $p=.048$; Table 3). Taller children had a lower SMFQ score with coefficients of $-0.30(p=.235)$ at 24 months and $-0.61(p=.155)$ at 120 months. However, taller children at 1 and 180 months had a higher SMFQ score with coefficients of $0.07(p=.785)$ and 0.68 $(p=.044)$, respectively (Table 3). Other than HAZ at 180 months of age, these associations did not reach statistical significance. This association was diluted and other results did not change when possible confounders and intermediate variables were included in the model (Models 2 and 3). Pubertal maturity and gender were not statistically significantly associated with depressive symptoms (Table 3). The results were similar when we further added the mode of administration to all the presented analyses (data not shown).

\section{4 | DISCUSSION}

The study's primary aim was to evaluate the prevalence of depressive symptoms among rural Malawian adolescents. In a cohort of 523 study participants, the prevalence of reported depressive symptoms was high. Over $90 \%$ of participants in our study had SMFQ scores higher than the Western cut-off value for screening for depression. This cut-off has not, however, been well validated in Malawi or in other African settings. The secondary aim was to assess the association between birth weight, height gain in childhood, gender, and pubertal maturity at the time of the assessment and depressive symptoms at 15 years. In the imputed data analysis, these factors did not predict depression. However, lower birth weight was associated with more frequent reported depressive symptoms in the complete data analysis. This association was consistent when possible confounders and intermediate variables were added to the model. Physically more mature participants had slightly more reported depressive symptoms, but this association did not reach statistical significance. Sex was not independently associated with depressive symptoms in any of the models.

The prevalence of reported depressive symptoms in our cohort was unexpectedly high. Turner and others have argued that the SMFQ may overestimate the prevalence of depression in individuals with lower educational attainment (Turner et al., 2014). This may be part of the explanation of the high proportion scoring above the cut-off. Our study did not reveal obvious predictors for the prevalence of depressive symptoms. In line with previous studies (Costello, 2007; de Mola, 2014), we found some signs of higher birth weight being associated with fewer depressive symptoms in adolescence. This may highlight the importance of intrauterine growth on later mental health. Our confidence intervals were, however, quite wide, and the association was not found in the imputed primary analysis. The difference in the results between these two analyses may be due to the cohort's large dropout rate. Neither height gain during childhood nor gender explained the magnitude of depressive symptoms. Pubertal maturity relates to depressive symptoms (Angold et al., 1998). There was some evidence of the effect of advanced puberty in our study, but the associations were not statistically significant. The reason for the absence of associations is not evident: either there are no associations or the high prevalence of depressive symptoms in our cohort 
TABLE 3 The association between birth weight and linear childhood growth and SMFQ scores at 15 years

\begin{tabular}{|c|c|c|c|c|c|c|}
\hline \multirow{3}{*}{ Regressor } & \multicolumn{2}{|l|}{ Model 1} & \multicolumn{2}{|l|}{ Model $2^{\mathrm{a}}$} & \multicolumn{2}{|l|}{ Model $3^{b}$} \\
\hline & \multicolumn{2}{|c|}{ Regression coefficient $[95 \% \mathrm{Cl}], p$ value } & \multicolumn{2}{|c|}{ Regression coefficient $[95 \% \mathrm{Cl}], p$ value } & \multicolumn{2}{|c|}{ Regression coefficient $[95 \% \mathrm{Cl}], p$ value } \\
\hline & Observed $(n=236)$ & Imputed $(n=523)$ & Observed $(n=236)$ & Imputed $(n=523)$ & Observed $(n=236)$ & Imputed $(n=523)$ \\
\hline HAZ_1 & $\begin{array}{l}0.07[-0.45-0.59] \\
\quad .785\end{array}$ & $\begin{array}{l}0.11[-0.34-0.60] \\
.643\end{array}$ & $\begin{array}{l}0.01[-0.53-0.55] \\
\quad .978\end{array}$ & $\begin{array}{l}0.07[-0.41-0.56] \\
\quad .765\end{array}$ & $\begin{array}{l}-0.01[-0.56-0.53], \\
.963\end{array}$ & $\begin{array}{l}0.06[-0.42-0.54] \\
\quad .800\end{array}$ \\
\hline HAZ_120 & $\begin{array}{l}-0.61[-1.44-0.23] \\
.155\end{array}$ & $\begin{array}{l}-0.03[-0.61-0.60], \\
.932\end{array}$ & $\begin{array}{l}-0.5[-1.56-055] \text {, } \\
.345\end{array}$ & $\begin{array}{l}-0.10[-0.85-0.66], \\
.793\end{array}$ & $\begin{array}{l}-0.53[-1.60-0.53] \\
\quad .324\end{array}$ & $\begin{array}{l}-0.15[-0.90-0.61], \\
.706\end{array}$ \\
\hline HAZ_180 & $\begin{array}{l}0.68 \text { [0.02-1.35] } \\
\quad .044\end{array}$ & $\begin{array}{l}0.15[-0.37-0.64] \\
\quad .559\end{array}$ & $\begin{array}{l}0.54[-0.32-1.40] \\
\quad .216\end{array}$ & $\begin{array}{l}0.21[-0.40-0.83] \\
\quad .497\end{array}$ & $\begin{array}{l}0.49[-0.38-1.36] \\
\quad .267\end{array}$ & $\begin{array}{l}0.16[-0.46-0.78] \\
\quad .614\end{array}$ \\
\hline Female & & & $\begin{array}{l}0.33[-1.01-1.67] \\
\quad .630\end{array}$ & $\begin{array}{l}-0.29[-1.28-0.69] \text {, } \\
.559\end{array}$ & $\begin{array}{l}0.37[-1.00-1.74] \\
\quad .596\end{array}$ & $\begin{array}{l}-0.31[-1.31-0.70] \\
\quad .550\end{array}$ \\
\hline
\end{tabular}

Note. HAZ = height-for-age z-scores; SMFQ = Short Mood and Feelings Questionnaire.

'The confounders included in Model 2 are gender, socio-economic level, gestational duration, father's occupation, father's literacy, and mother's literacy. 'The confounders and moderators included in Model 3 are gender, socio-economic level, gestational duration, father's occupation, father's literacy, mother's literacy, pubertal maturity, and the Raven's Coloured Matrices score.

leads to too little variation and the differences cannot be distinguished with the tool used. There may also be some characteristics in depression morbidity in low-income countries that differ from those in the West. Most of the evidence of the association between early growth and depression comes from developed countries (Costello, 2007, de Mola, 2014). It was not possible to investigate these potential differences in this study.

We believe that our results may be generalized to the target population. The anthropometric measurements used in this study were taken by trained data collectors with proper, regularly calibrated equipment. Participant characteristics were similar in the included and the excluded groups, with the exception of birth weight, which was lower in the excluded group. Average birth weight was within normal range in both groups, however, and there was no significant difference in the proportion of children with low birth weight. In additional analyses with all the original participants included, the results were similar.

This study has some limitations. The SMFQ has not been validated in our study setting; however, the questionnaire was carefully translated and back-translated until all the inaccuracies were detected. The concept and vocabulary concerning mental health may have been unfamiliar to the participants in the study site, considering the poor awareness of mental health problems and services. The SMQF was mostly administered by interview rather than self-administration. However, interviews tend to underestimate rather than overestimate the prevalence of mental health problems (Waal, Weele, Mast, Assendelft, \& Gussekloo, 2012). Hence, the high prevalence of symptoms in our cohort is most likely not due to the questionnaires' mode of administration.

The SMFQ is widely used, including in low-income settings and among adolescents (Ali, Ryan, \& De Silva, 2016; Allison \& Ferreira, 2017; Bjelland, Dahl, Haug, \& Neckelmann, 2002; Turner et al., 2014). It has shown promise as a reliable and valid instrument for the assessment of depressive symptoms among adolescents in Bangladesh, but the study did not establish a cut-off score for classifying clinical depression status (Deeba, Rapee, \& Prvan, 2015). SMFQ was developed as a screening tool. The sensitivity and the specificity of SMFQ are $71 \%$ and $83 \%$, respectively (Turner et al., 2014). Not all of the screen positive participants may have clinically significant depressive symptoms. Individual questions in the SMFQ are mostly unambiguous, and there are no specific questions which raise obvious concerns about misinterpretation. However, there may still be cultural or language related factors that affect the results. Therefore, one may argue that the traditionally used cut-off may be too low in this rural African setting. However, even if the cut-off was raised to as high as 20 points, approximately $12 \%$ of the participants would still be classified as having a high level of reported symptoms. We did not collect data on the mothers' depression or mental health, which may contribute to the depressive symptoms of the offspring (Patel et al., 2007). The SMQF was only administered at 15 years of age, not at any other time points. The weight measurements taken during the first 7 days of life give a reasonable estimate of the size of the participants at birth.

Our findings highlight the importance of the awareness of depressive symptoms and resource allocation in low-income countries. Further research is needed to validate the SMFQ and establish a cut-off score for clinically significant depressive symptoms in rural Malawi. Validation should be carried out against definitive diagnoses and conducted by a culturally embedded child and adolescent psychiatrists. Alternatively, it may be necessary to use a different tool to assess depressive symptoms. Possible differences in the associations between developed and low-income countries remain unknown.

\section{ACKNOWLEDGEMENTS}

We are grateful for all the Lungwena Child Survival Study participants, their parents, and the staff at the study clinic. We also thank Academy of Finland for funding this study. 


\section{FUNDING INFORMATION}

All the direct research expenses for designing and conducting the study collection, management, analysis, and interpretation of the data, preparation, review, approval of the manuscript, and decision to submit the manuscript for publication were covered by an Academy of Finland grant (grant 252075) to Professor Per Ashorn in University of Tampere. T. T. received salary from University of Tampere and National School of Clinical Investigation and personal stipends awarded to her by Finnish Cultural Foundation, Häme Regional Fund, Foundation for Pediatric Research, and The Research Foundation of the Pulmonary Diseases.

\section{CONFLICT OF INTEREST STATEMENT}

None of the authors had conflict of interest.

\section{CONTRIBUTOR STATEMENT}

The authors' responsibilities were as follows. P. A. and K. M. formed the original cohort and conducted the early data collection. T. T., Y. B. C., and P. A. were responsible for the current research design, and T. T. conducted the study. T. T. and Y. B. C. performed and are responsible for the data analysis. $T$. T. wrote the first draft of the manuscript, Y. B. C., K. M., M. G. and P. A. were involved in data interpretation and writing the final version of the manuscript. All authors read and approved the final manuscript. T. T. had primary responsibility for the final content.

\section{ORCID}

T. Teivaanmäki (D) http://orcid.org/0000-0002-8143-506X

\section{REFERENCES}

Ali, G., Ryan, G., \& De Silva, M. (2016). Validated screening tools for common mental disorders in low and middle income countries: A systematic review. PLoS one, 11(6), e0156939.

Allison, A. C., \& Ferreira, R. J. (2017). 2016, "Implementing cognitive behavioral intervention for trauma in schools (CBITS) with Latino youth". Child and Adolescent Social Work Journal, 34(2), 181-189.

Angold, A., Costello, E., Messer, S., Pickles, A., Winder, F., \& Silver, D. (1995). Development of a short questionnaire for use in epidemiological studies of depression in children and adolescents. International Journal of Methods in Psychiatric Research, 5(4), 237-249.

Angold, A., Costello, E. J., \& Worthman, C. M. (1998). Puberty and depression: The roles of age, pubertal status and pubertal timing. Psychological Medicine, 28(1), 51-61.

Bjelland, I., Dahl, A. A., Haug, T. T., \& Neckelmann, D. (2002). The validity of the hospital anxiety and depression scale: An updated literature review. Journal of Psychosomatic Research, 52(2), 69-77.

Cortina, M. A., Sodha, A., Fazel, M., \& Ramchandani, P. G. (2012). Prevalence of child mental health problems in sub-Saharan Africa: A systematic review. Archives of Pediatrics and Adolescent Medicine, 166(3), 276-281.

Costello, E. J. (2007). Prediction from low birth weight to female adolescent depression: A test of competing hypotheses. Archives of General Psychiatry, 64(3), 343.

De Onis, M., Onyango, A. W., Borghi, E., Siyam, A., Nishida, C., \& Siekmann, J. (2007). Development of a WHO growth reference for school-aged children and adolescents. Bulletin of the World Health Organization, 85(9), 660-667. de Mola, C. L. (2014). Low birth weight, preterm birth and small for gestational age association with adult depression: Systematic review and meta-analysis. The British Journal of Psychiatry, 205(5), 340.

de Mola, C. L., Quevedo, L. d. A., Pinheiro, R. T., Gonçalves, H., Gigante, D. P., Motta, V. d. S., ... Horta, B. L. (2015). The effect of fetal and childhood growth over depression in early adulthood in a southern Brazilian birth cohort. PLoS one, 10(10), e0140621.

Deeba, F., Rapee, R. M., \& Prvan, T. (2015). Psychometric properties of two measures of childhood internalizing problems in a Bangladeshi sample. British Journal of Clinical Psychology, 54(2), 214-232.

Filmer, D., \& Pritchett, L. H. (2001). Estimating wealth effects without expenditure data-or tears: An application to educational enrollments in states of India. Demography, 38(1), 115-132.

Galler, J. R., Bryce, C. P., Waber, D., Hock, R. S., Exner, N., Eaglesfield, D., ... Harrison, R. (2010). Early childhood malnutrition predicts depressive symptoms at ages 11-17. Journal of Child Psychology \& Psychiatry, 51(7), 789-798.

Kulmala, T., Vaahtera, M., Ndekha, M., Koivisto, A., Cullinan, T., Salin, M., \& Ashorn, P. (2000). The importance of preterm births for peri- and neonatal mortality in rural Malawi. Paediatric and Perinatal Epidemiology, 14(3), 219-226.

Maleta, K., Virtanen, S., Espo, M., Kulmala, T., \& Ashorn, P. (2003). Timing of growth faltering in rural Malawi. Archives of Disease in Childhood 88(7), 574-578.

Patel, V., Flisher, A., Hetrick, S., \& McGorry, P. (2007). Adolescent Health 3 -Mental health of young people: A global public-health challenge. Lancet, 369(9569), 1302-1313.

Proos, L. (2012). Is early puberty triggered by catch-up growth following undernutrition? International Journal of Environmental Research \& Public Health Electronic Resource, 9(5), 1791-1809.

Raven, J., Raven, J., \& Court, J. (1998). Manual for Raven's progressive matrices and vocabulary scales. Section 2: The coloured progressive matrices. San Antonio, TX: Harcourt Assessment.

Rubin, D. B. (1987). Multiple imputation for nonresponse in surveys. New York: Wiley.

Tanner, J. (1962). Growth at adolescence. Oxford: Blackwell Scientific Publications.

Teivaanmäki, T., Bun Cheung, Y., Pulakka, A., Virkkala, J., Maleta, K., \& Ashorn, P. (2017). Height gain after two-years-of-age is associated with better cognitive capacity, measured with Raven's coloured matrices at 15-years-of-age in Malawi: Height gain is associated with cognitive capacity. Maternal \& Child Nutrition https://doi.org/10.1111/ mcn.12326.

Teivaanmaki, T., Cheung, Y. B., Kortekangas, E., Maleta, K., \& Ashorn, P. (2015). Transition between stunted and nonstunted status: both occur from birth to 15 years of age in Malawi children. Acta Paediatrica 104(12), 1278-1285.

Thompson, R. A. (2001). Developmental science and the media. Early brain development. American Psychologist, 56(1), 5-15.

Turner, N., Joinson, C., Peters, T., Wiles, N., \& Lewis, G. (2014). Validity of the Short Mood and Feelings Questionnaire in late adolescence. Psychological Assessment, 26(3), 752-762.

Vidmar, S. I., Cole, T. J., \& Pan, H. (2013). Standardizing anthropometric measures in children and adolescents with functions for egen: Update. Stata Journal, 13(2), 366-378.

Waal, M. W.d., Weele, G. M.v.d., Mast, R. C.v.d., Assendelft, W. J. J., \& Gussekloo, J. (2012). The influence of the administration method on scores of the 15-item Geriatric Depression Scale in old age. Psychiatry Research, 197(3), 280-284.

Walker, S. P., Chang, S. M., Powell, C. A., Simonoff, E., \& GranthamMcGregor, S. M. (2007). Early childhood stunting is associated with poor psychological functioning in late adolescence and effects are reduced by psychosocial stimulation. Journal of Nutrition, 137(11), 2464-2469. 
White, I. R., Royston, P., \& Wood, A. M. (2011). Multiple imputation using chained equations: Issues and guidance for practice. Statistics in Medicine, 30(4), 377-399.

WHO Multicentre Growth Reference Study Group (2006). WHO child growth standards: Length/height-for-age, weight-for-age, weight-forlength, weight-for-height and body mass index-for-age: Methods and development. Geneva: World Health Organization.

World Health Organization. WHO (2008). The Global Burden of Disease 2004 Update.
How to cite this article: Teivaanmäki T, Cheung YB, Maleta K, Gandhi M, Ashorn P. Depressive symptoms are common among rural Malawian adolescents. Child Care Health Dev. 2018;44:531-538. https://doi.org/10.1111/cch.12567 